\title{
The Development of Adolescent Chronic Pain following Traumatic Brain Injury and Surgery: The Role of Diet and Early Life Stress
}

\author{
Sabrina Salberg ${ }^{a}$ Marissa Sgro ${ }^{a}$ Rhys D. Brady ${ }^{a}$ Melanie Noel ${ }^{b}$ \\ Richelle Mychasiuk ${ }^{a}$ \\ ${ }^{a}$ Department of Neuroscience, Central Clinical School/Monash University, Melbourne, VIC, Australia; \\ ${ }^{b}$ Department of Psychology, Alberta Children's Hospital Research Institute, Hotchkiss Brain Institute/ \\ The University of Calgary, Calgary, AB, Canada
}

\section{Keywords}

Microglia · Adverse childhood experiences · HPA axis ·

Neuroinflammation

\begin{abstract}
Pain is evolutionarily necessary for survival in that it reduces tissue damage by signaling the body to respond to a harmful stimulus. However, in many circumstances, acute pain becomes chronic, and this is often dysfunctional. Adolescent chronic pain is a growing epidemic with an unknown etiology and limited effective treatment options. Given that the relationship between acute pain and chronic pain is not straightforward, there is a need to better understand the factors that contribute to the chronification of pain. Since early life factors are critical to a variety of outcomes in the developmental and adolescent periods, they pose promise as potential mechanisms that may underlie the transition from acute to chronic pain. This review examines two early life factors: poor diet and adverse childhood experiences (ACEs); they may increase susceptibility to the development of chronic pain following surgical procedures or traumatic brain injury (TBI). Beyond their high prevalence, surgical procedures and $\mathrm{TBI}$ are ideal models to prospectively understand
\end{abstract}

mechanisms underlying the transition from acute to chronic pain. Common themes that emerged from the examination of poor diet and ACEs as mechanisms underlying this transition included: prolonged inflammation and microglia activation leading to sensitization of the pain system, and stressinduced alterations to hypothalamic-pituitary-adrenal axis function, where cortisol is likely playing a role in the development of chronic pain. These areas provide promising targets for interventions, the development of diagnostic biomarkers, and suggest that biological treatment strategies should focus on regulating the neuroinflammatory and stress responses in an effort to modulate and prevent the development of chronic pain.

๑ 2020 S. Karger AG, Basel

\section{Introduction}

All youth experience acute pain, and although many recover quickly, a significant proportion develop chronic pain. Chronic pain (i.e., pain lasting $>3$ months) is a growing epidemic with limited effective treatment options [1]. Pediatric chronic pain most often emerges in the adolescent period, and disproportionately affects karger@karger.com

www.karger.com/dne

(c) 2020 S. Karger AG, Base

Karger ${ }^{\prime}=$
Richelle Mychasiuk

Department of Neuroscience, Central Clinical School/Monash University 6th Floor, 99 Commercial Road

Melbourne, VIC 3004 (Australia)

Richelle.mychasiuk@monash.edu 
girls, with prevalence rates of $11-38 \%$, roughly twice that of their male counterparts [2]. The impacts are widereaching and include missed school, reduced social and athletic activities, and mental health disorders [3]. Up to $60 \%$ of youth with chronic pain continue to suffer from chronic pain as adults [4]. This can lead to lost productivity in the workforce and cost the health care system billions of dollars [3]. Considering acute pain presents without any indication it will persist, the difficulty lies in catching its transition to chronic pain before it develops [5]. Given that we currently do not know why chronic pain develops and persists during this critical maturational period, this is a growing public health epidemic.

\section{Critical Windows of Development}

In order to survive, an organism must be able to adapt to its environment. These adaptations occur during critical windows of development as a result of genetics and epigenetics. This concept, known as programming theory, postulates that during critical periods of plasticity, organisms can permanently alter systems and their functions [6]. Although this can produce advantageous adaptations, this programming may be maladaptive and predispose an individual to disease if environmental conditions prenatally, or in early life, do not match environmental conditions later in life [6]. For instance, prenatal stress can program a persistently hyperactive hypothalamic-pituitary-adrenal (HPA) axis and lead to exaggerated responses to stress in offspring [6]. The brain is particularly vulnerable to input during childhood and adolescence as this is a critical window of plasticity and growth [7]. Early life factors are therefore crucial in explaining why outcomes later in life can differ when two individuals are exposed to similar experiences.

Adolescence is a critical developmental period characterized by the onset of puberty, which begins between 8 and 15 years of age with earlier onset for girls versus boys [8]. These maturational changes include the development of secondary sex characteristics, triggered by the activation of the HPA axis, as well as dramatic hormonal changes, increases in white matter volume and anisotropy, and decreases in total cerebral and grey matter volumes [810]. These brain changes are thought to be associated with increased myelination and synaptic pruning that refine the neurocircuitry of the brain $[9,11]$. The prefrontal cortex (PFC), responsible for higher cognitive and executive functions, continues to develop into the third decade of life and undergoes significant maturation during adolescence $[12,13]$. The resulting outcomes associated with these brain changes are improved executive functioning, long-range planning, delayed gratification, and regulation of emotion $[9,11]$. Behaviors such as risk taking and sensation seeking also increase, in response to increases in activity of the nucleus accumbens, a brain region playing an important role in motivation and reward $[11,14]$. Further, the onset of mental health disorders peaks during adolescence, which is thought to be due to anomalies or exaggerations in typical adolescent-dependent brain changes $[14,15]$. Given drastic changes that occur during adolescence, it is likely that environmental factors have significant and long-lasting effects that can permanently alter normal developmental trajectories [16].

\section{Purpose of Review}

The pain response plays a crucial role in survival, allowing for the instinctual removal of a harmful stimulus, without which tissue damage could become irreparable before it is registered [17]. Like any system, however, it can malfunction, and chronic pain can arise. Although the impact of chronic pain is substantial, the etiology remains largely unknown, and treatments are often ineffective. While numerous etiological factors have been hypothesized, this review will examine two prenatal and early postnatal factors of particular promise. Specifically, in this review we hypothesize and demonstrate that a high-fat diet and early life trauma can influence the development of chronic pain in adolescence following surgical procedures or traumatic brain injury (TBI). Given that for adolescents, surgical procedures and TBI are: (a) prospective models that can identify risk before chronic pain develops and (b) both are at-risk populations for chronic pain (exhibiting an approximate increased incidence of $20 \%$ post-procedure/injury [18-24]), these are two pain-provoking outcomes that warranted investigation. Further, the high incidence rates of both surgical procedures and TBI, suggest that advancements made within this realm have the potential to significantly reduce the lifelong burden of chronic pain.

\section{Pain}

Pain is defined as "an unpleasant sensory and emotional experience associated with actual or potential tissue damage or described in terms of such damage" [25]. The experience of pain is complex and varies depending not only on the stimulus, but also on how it is perceived by the individual. Thus, the full experience of pain is primarily measured in humans who are able to communicate their subjective experience. In contrast, nociception 
Fig. 1. Simplified summary of the pain pathway and pain matrix. (1) External stimuli registered by $\mathrm{A} \delta$ or $\mathrm{C}$ nociceptive fibers. (2) Signal is transduced to the dorsal horn of the spinal cord. For a nociceptive stimulus (solid line), signal crosses to the contralateral side of the dorsal horn and travels to the brain via the anterior spinothalamic tract. For a hapsis stimulus (dashed line), the signal travels ipsilaterally in the spinal cord to the brain via the posterior spinothalamic tract. (3) Signal is then transduced to the brainstem where the posterior tract crosses contralaterally. (4) Signal then arrives at the thalamus, which relays to the appropriate brain regions in the pain matrix. Blue regions represent areas involved in sensory and acute perception of pain, while pink areas represent more cognitive and chronic processing of pain. S1, primary somatosensory cortex; S2, secondary somatosensory cortex; ACC, anterior cingulate cortex; PFC, prefrontal cortex.

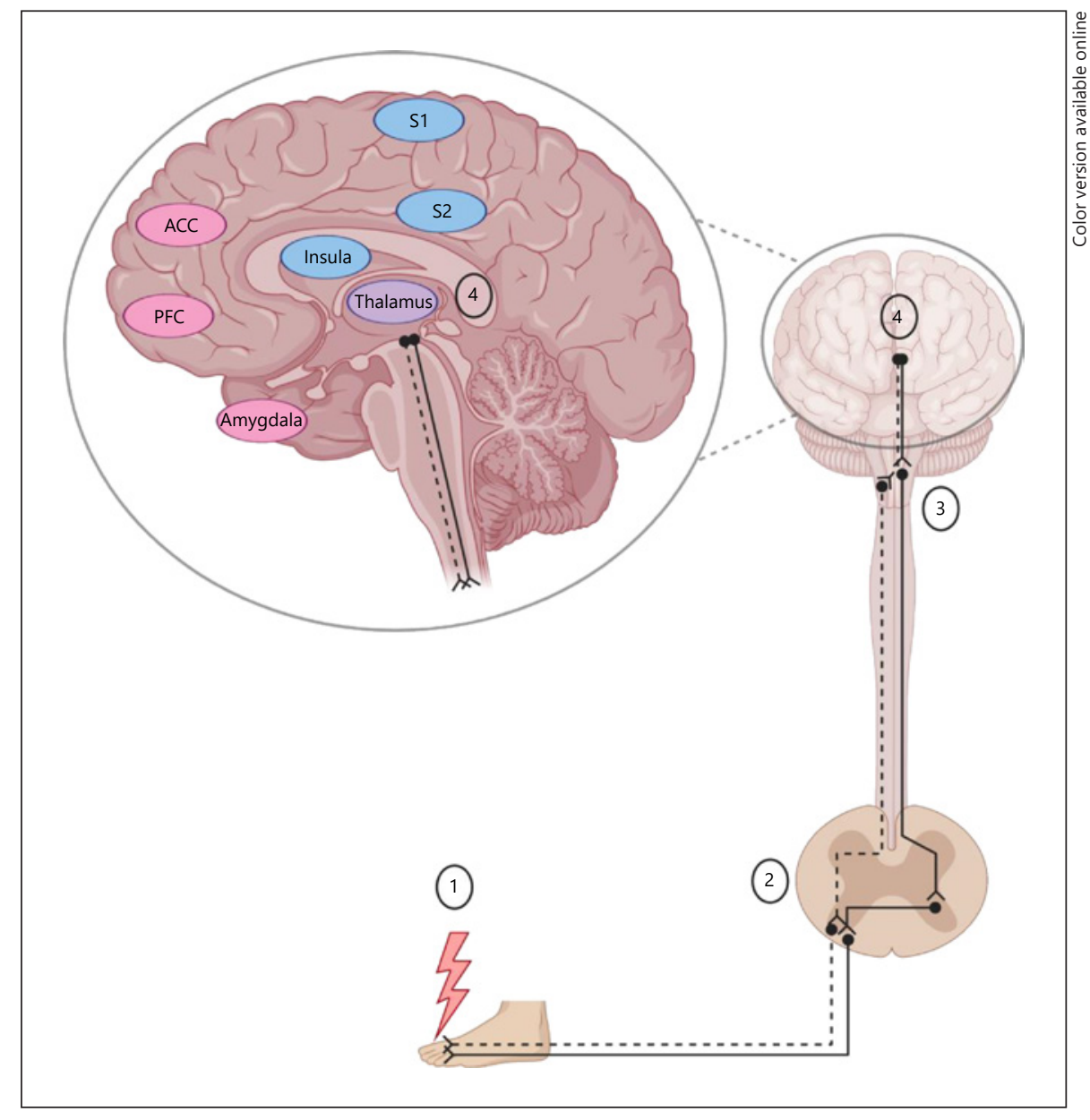

refers to the physical process in which nociceptors are stimulated and the signal is transmitted to the brain via the pain pathway [26]. Therefore, in preclinical studies, nociception is used to describe "pain" as the animals' responses to a stimulus are recorded, but subjective experiences are generally not measured.

Pain is most commonly registered as an external noxious stimulus by nociceptors in the affected area. When this happens, nociceptive fibers ( $\mathrm{C}$ or $\mathrm{A} \delta$ ) become depolarized, and with enough intensity and magnitude, generate an action potential [27]. The signal is conducted into the spinal cord via the dorsal horn, then to the brain via the contralateral spinothalamic, spinohypothalamic, spinoreticular, or spinomesencephalic tracts [27]. Where the signal ends up, and the pathway it took, depends on the type of nociceptors stimulated, and which laminae the afferent nociceptor enters the dorsal horn in $[27,28]$. For instance, $\mathrm{A} \delta$ fibers are myelinated and respond to sharp mechanical or thermal changes, while $\mathrm{C}$ fibers are unmy- elinated and respond to a more diffuse mechanical, thermal, or chemical stimuli [27-29] (see Fig. 1).

Several brain regions are involved in the pain pathway, termed the "pain matrix": primary somatosensory cortex (S1), secondary somatosensory cortex (S2), insular cortex (IC), anterior cingulate cortex (ACC), thalamus, amygdala, and frontal cortices $[27,30]$. The somatosensory cortices are involved in determining the sensory features (i.e., location, intensity) of the noxious stimulus $[27,30]$. The insula plays a role in detecting the intensity and laterality of any stimulus, and integrates information from different systems $[27,30]$. The amygdala and ACC play a role in the affective/cognitive processing of pain, while the $\mathrm{PFC}$ is related to cognitive aspects of pain, such as attention, memory, and evaluation $[27,30]$. The thalamus (i.e., the brain's relay station) takes in sensory information and directs it to appropriate brain regions for processing [31].

Evolutionarily, pain plays a critical role in survival [32]. It signals the body to withdraw or stop an action if 
causing damage [17]. Thus, acute pain is a healthy, evolutionarily essential process. In normal conditions, a cascade of proinflammatory substances, such as interleukin-6 (IL-6), interleukin-1 beta (IL-1 $\beta$ ), and tumor necrosis factor alpha $(\mathrm{TNF} \alpha)$, are released following acute tissue damage, causing inflammation at the injury site [33]. This peripheral inflammation causes various enzymes, substance $\mathrm{P}$, and nitric oxide to be released, further contributing to inflammation, potentiating nociception, and increasing excitability [33]. The injury site is then sensitive, encouraging the individual to avoid further contact and thus protecting it from damage.

\section{The Development of Chronic Pain}

Contrary to acute pain, chronic pain is not a normal, necessary response. It can occur with continued nociceptive stimulation in response to an unresolved physiological condition or may persist without identifiable causes [29]. In chronic pain, a persistent stimulus may cause peripheral and/or central sensitization [27]. Peripheral sensitization can be caused by prolonged inflammation, leading to hyperexcitability of nociceptors and resulting in hyperalgesia (an enhanced response to a noxious stimulus) [27]. Central sensitization occurs within the central nervous system (CNS) and may result in allodynia (i.e., evoked pain in response to a normally non-noxious stimulus) $[27,29,33]$. In this case, $A \beta$ fibers are recruited, which are normally innocuous mechanoreceptors [27, 29, 33]. Thus, the factors involved in chronic pain are likely outside of the sensory acute pain pathway.

Acutely painful stimuli can lead to the development of chronic pain. Chronic pain often stems from an acutely painful incident, with pain persisting beyond the normative time of maximal physical healing [34]. Many experiences can be acutely painful; however, this review focuses on surgery and TBI as they are particularly prevalent in adolescent populations. Alarmingly, nearly $20 \%$ of youth will develop chronic pain post-TBI and surgery making them ideal models to prospectively understand transition from acute to chronic pain [18-24]. While the literature surrounding post-surgical pain is abundant, post-traumatic pain is less well studied, especially within the context of mild TBI and concussion.

\section{Diet and the Development of Chronic Pain}

Since 1975, obesity rates have tripled in adults and quadrupled in youth [35]. A healthy diet is crucial for maintaining an optimal balance of nutrients and overall health. However, much of the Western world, particularly those of lower socioeconomic status, consumes an excessive amount of unhealthy fats and sugars, which can have serious health complications [36, 37]. This high-fat, high-sugar (HFHS) or "Western diet" results in spatial memory and learning problems, decreased neuronal resiliency to oxidation or other insults, and reductions in neuroplasticity and brain-derived neurotrophic factor in the hippocampus [38-40]. Further, HFHS diets have been associated with reduced synaptic plasticity in the PFC, and impaired function in the amygdala and HPA axis of adolescents $[39,41]$.

This HFHS "Western Diet" can lead to obesity, which is associated with an array of health issues, including diabetes, cardiovascular disease, hypertension, and osteoarthritis $[36,42]$. A less evident consequence of this diet is chronic low-grade inflammation [43, 44]. Neurological inflammation results from an immune response in which microglia act to protect the CNS [44]. Microglia act via phagocytosis, engulfing damaged cells and pathogens [45]. They also release proinflammatory cytokines, such as IL-6, IL-1 $\beta$, and TNFa to protect and repair cells [46, 47]. However, persistent or over-activation of microglia, such as in response to systemic inflammation, can disrupt microglia function and become harmful [45]. Microglia can consume neurons and tissue and disrupt normal pathways. Moreover, checkpoints of the microglial inflammatory response can result in neurodegeneration $[45,46]$.

\section{Maternal Diet}

Maternal obesity results in increased inflammation for both the mother and the developing fetus, which can lead to cognitive deficits and adverse health outcomes in offspring [48]. With one-third of mothers entering pregnancy overweight, it is crucial to understand the resulting impact of this epidemic on developing fetuses [48]. For instance, Igosheva et al. [49] found that even before conception, oocytes of diet-induced obese mice exhibit elevations in reactive oxygen species (ROS), which propagated into zygote formation. Given the link between ROS and pain is well established; this demonstrates a possible avenue for the development of pain in offspring of obese mothers [50-53]. Further, rats born to dams fed a high-fat diet had increases in proinflammatory cytokine IL-6 and glial markers ionized calcium binding adaptor molecule 1 (Iba1) and glial fibrillary acidic protein (GFAP) in the brain [40, 54-56]. Maternal obesity may prime placental macrophage and fetal brain microglial cells to overrespond to later immune challenges [48]. 
These macrophages and microglia were shown to overproduce the proinflammatory cytokine TNFa in response to an immune challenge in the fetal brains [48]. This demonstrates that maternal obesity may impose long-lasting effects on the innate immune response of the offspring CNS, priming dysregulation of neuroimmune function [48]. Currently, it is evident that maternal diet-induced obesity causes microglia activation and inflammation in offspring. Given the potential for maternal diet to produce long-term alterations in neuroimmune function of offspring, it is plausible that a later injury or infection could lead to an excessive and persistent response.

\section{Child Diet}

Although maternal diet likely has an effect on persistent health outcomes, the diet of the developing child can also influence long-term trajectories. Many clinical studies have observed an association between obesity and chronic pain. Musculoskeletal pain and recurrent abdominal pain have been positively associated with increased weight $[57,58]$. Although the association between obesity and chronic pain has been robustly observed in clinical populations, there is a gap in the literature regarding mechanisms underlying this association.

Nevertheless, inflammation is a likely culprit. Mice fed a diet high in saturated fats, versus a standard diet, showed proinflammatory microglia expansion, providing evidence that diet influences microglia function [59]. Although pain was not directly measured, this increase in microglia activation would likely exacerbate inflammation and influence pain outcomes. In a single study, juvenile rats fed the ketogenic diet (a high-fat, low-carbohydrate diet that has been shown to reduce ROS and inflammation) exhibited thermal hypoalgesia (i.e., decreased sensitivity to thermally derived pain stimuli), thereby demonstrating that diet can influence pain sensitivity by modulating inflammatory processes [60]. Thus, it is reasonable to hypothesize that a diet that encourages inflammation, such as the HFHS "Western diet," may have the opposite effect and induce hyperalgesia.

\section{Diet and Chronic Pain}

Despite a link between diet and pain, there is a dearth of research on underlying mechanisms. Limited preclinical studies point to microglial activation and inflammation, with proinflammatory cytokines that activate nociceptive sensory neurons being a key factor in the transition from acute to chronic pain [61]. For example, primed microglia may play a significant role in the development of post-surgical pain. In a rodent surgery model, microg- lia activation was prolonged, and allodynia was enhanced following a later immune challenge [62]. Microglia are macrophages of the brain, and the main form of immune defense in the CNS [63]. They protect the brain by responding to any pathological state, including injury, infection, or increased ROS $[46,63]$. In a primed state, microglia can overrespond to later challenges with excessive levels of proinflammatory cytokines [62]. This exacerbated neuroinflammatory response may lead to post-surgical allodynia [62].

Similarly, in the context of post-traumatic pain, the increased inflammation and microglia activation associated with HFHS diets may increase one's risk for post-TBI migraine and headache. Post-traumatic migraine and headaches are thought to occur in response to changes in cerebral blood flow, prolonged release of excitatory amino acids, and ionic imbalance (increased extracellular potassium and intracellular calcium) that results in cortical depression $[64,65]$. Only recently was a rodent model of headache-related behavior after concussion developed, opening up the possibility for better investigation of the mechanism driving this relationship. This study hypothesized that cephalic allodynia was due to inflammatory activation and sensitization of meningeal afferents and, in turn, central trigeminal dorsal horn neurons [66]. It was posited that TBI promotes a migraine/headache phenotype that involves sensitivity to common triggers [66], which could be exacerbated by diet-induced neuroinflammation. Therefore, it is reasonable to suggest that diet has the potential to be a risk factor for the development of chronic pain and may be a promising target for new avenues in prevention, assessment, and treatment of chronic pain.

\section{Adverse Childhood Experiences and the Development of Chronic Pain}

Adverse childhood experiences (ACEs) include physical, sexual, and emotional abuse, neglect, and household dysfunction occurring early in life [67] and have been associated with cognitive, social, and emotional impairment, and more recently, chronic pain [68-70]. Such trauma can be physical or psychological, with the former's implications in chronic pain being well established, and with growing evidence for the latter's $[68,71,72]$. Proposed underlying mechanisms involve increased HPA axis activity due to increased stress [73, 74], which has been observed in chronic pain patients. Thus, this cumulative dysfunction may impact pain responsivity [75]. 
Cortisol is responsible for initiating a rapid response to threats by maintaining high levels of glucose [17]. It does so by breaking down protein in muscle and inhibiting the replacement of calcium in bone, which is associated with an increased risk of bone fracture. In addition, increased cortisol levels can cause myopathy, weakness, fatigue, suppressed immune system, and accelerated hippocampal degeneration in aging $[17,76]$. Hypocortisolism, which could be caused by prolonged stress-depletion of cortisol, has been linked to fibromyalgia, rheumatoid arthritis, and chronic fatigue syndrome [17].

\section{Maternal ACEs}

Early life stress can have a profound impact on an individual's health and may induce intergenerational dysfunction. Maternal ACEs have been associated with worse psychosocial health in offspring [77]. Further, in extreme cases, such as children of Holocaust survivors, maternal ACEs affected both the mental and physical health of their offspring $[78,79]$. Not only does maternal childhood adversity affect the psychological well-being of offspring, it is associated with the incidence of traumatic events in children. For example, maternal abuse has been correlated with offspring victimization [80]. Mothers who experienced trauma often have impaired stress responses and socio-emotional functioning, which can lead to increased risk taking behavior (e.g., substance abuse) and, therefore, ACEs in their children [80]. This can lead to a viscous intergenerational cycle of trauma that, if appropriately addressed, would lead to healthier future generations.

Maternal distress directly impacted offspring pain, predicting recurrent abdominal pain [81], with increased maternal cortisol levels influencing cortisol levels in infants [82]. Similarly, prenatal stress in a rodent model increased basal levels of proinflammatory cytokines IL- $1 \beta$ and $\mathrm{TNF} \alpha$, as well as reactive microglia in the hippocampus of offspring [83]. Further, these prenatally stressed mice showed increased levels of corticosterone, and increased expression of GFAP, Iba1, and TNFa in the dentate gyrus, following a later immune challenge [83]. This suggests prenatal stress promoted a basal proinflammatory state, resulting in exaggerated microglia response to a later insult in offspring.

\section{Child ACEs}

ACEs directly and adversely affect the individual experiencing them. Retrospective clinical studies have described an association between traumatic events and chronic pain [84-88]. An increase in childhood abuse correlates with more reported pain, and increased adverse events, such as institutional care or familial financial hardship, correlate with chronic widespread pain [70, 86, 87]. For instance, childhood sexual abuse is associated with increased rates of chronic pelvic pain [88]. Psychological trauma early in life also increases levels of proinflammatory markers, such as TNFa, IL-6, and C-reactive protein, into adulthood [89]. This programming of neuroimmune function to a proinflammatory state may be due to epigenetic alteration of the HPA axis and the glucocorticoid receptor, which regulates inflammatory activity, and can lead to an exaggerated proinflammatory cytokine and microglia response to later immune challenges $[83,89,90]$.

Although the mechanisms underlying the association between ACEs and pain are not confirmed, preclinical studies are beginning to tackle this gap in knowledge. By modelling neglect via maternal separation or deprivation paradigms, rodent pups are exposed to ACEs. By exposing animals to early stressful conditions, their nervous, endocrine, and immune systems adapt and program to cope with that environment [91]. However, when housed in non-stressful environments later in life, this adaptation can be maladaptive and lead to behavioral impairments and psychological symptoms, such as anxiety [91]. Results from such studies have also shown increased pain sensitivity, altered nociceptive responding, and changes to circulating levels of inflammatory markers [92, 93]. This has led researchers to hypothesize that epigenetic changes in response to the early childhood trauma may be implicated. For example, expression of both the glucocorticoid receptor, responsible for binding cortisol, and glial cells has been shown to be altered, which may lead to changes in inflammation and the development of persistent pain $[92,93]$. Further evidence from animal studies supports the clinical literature, in which childhood trauma results in emotional dysfunction, whereby altered microglia activation was associated with increased anxietylike and depressive-like behaviors (psychological factors often comorbid with chronic pain) $[94,95]$. Thus, an altered microglia response can in turn modify inflammatory processes, which is emerging as a common factor in the development of maladaptive pain.

\section{ACEs and Chronic Pain}

Stress and chronic pain have a bidirectional relationship, with chronic pain being influenced by stress, and posing as a stressor itself, exacerbating poor functioning [96]. Stressful environments are strongly associated with child disability and other physical and mental health disorders [96]. The nature of ACEs suggests that survivors will experience significant psychological distress, altering HPA axis 
Fig. 2. Summary of the potential mechanisms underlying the respective factors' contribution to the development of chronic pain.

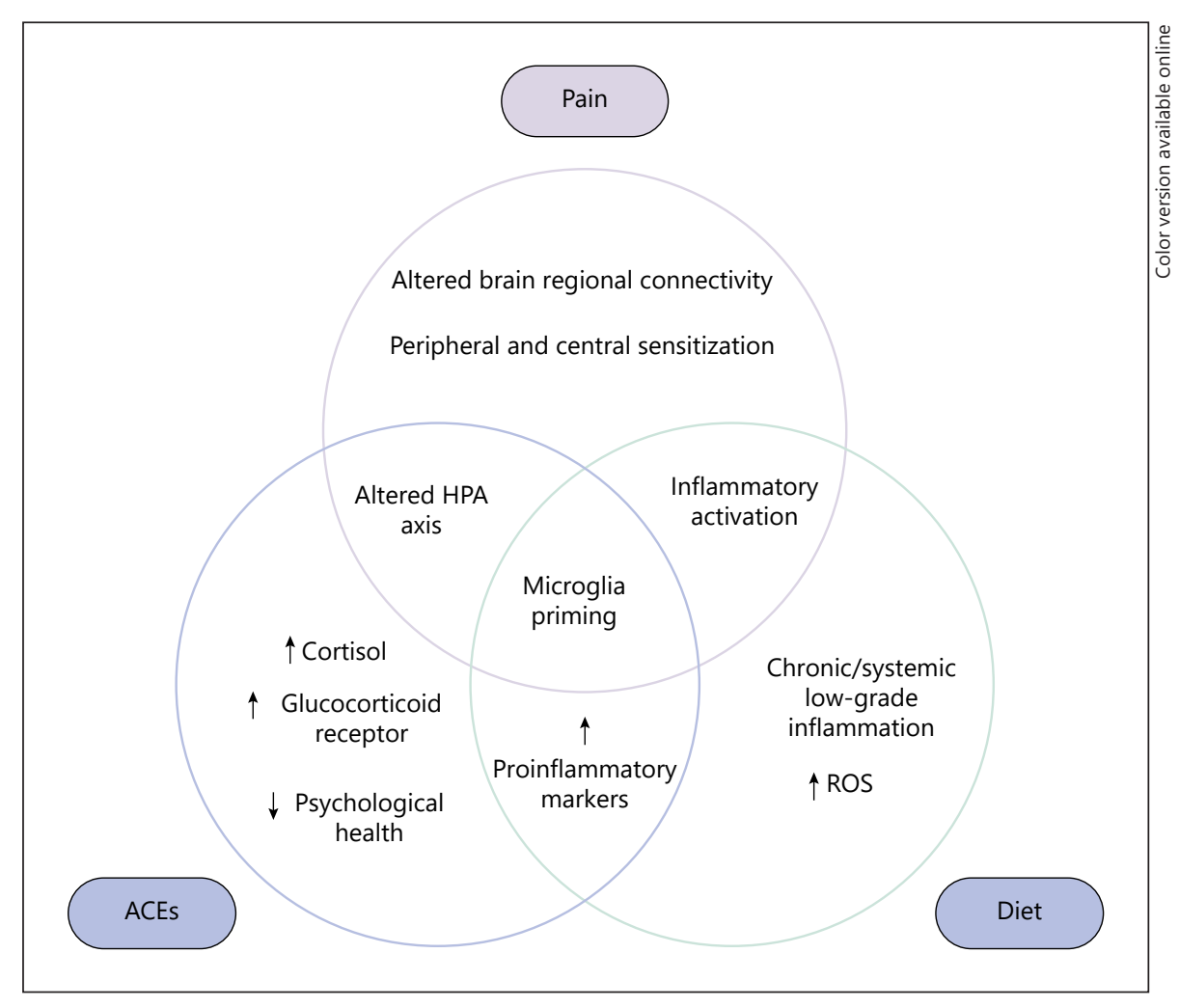

function and cortisol levels [17, 73, 74]. The underlying mechanisms are likely complex but involve physiological dysregulation of the HPA axis due to prolonged stress activation [96]. Given that TBI and ACEs have both been demonstrated to significantly modify the HPA axis and in turn subsequent cortisol levels [97-99], and altered cortisol release in combination with dysfunctional hypothalamic activity has been implicated in headache and migraine pain [100], it is reasonable to postulate that ACEs could exacerbate, worsen, or prolong post-traumatic headache pain. Maladaptation due to prenatal and early postnatal stress may also influence inflammatory markers, prime microglia to overrespond, and alter gene expression, all of which contribute to increased inflammation and susceptibility to persistent pain [83, 89, 91-93, 101-103].

Similar pathogenic mechanisms may be at play in the context of post-surgical pain. HPA axis dysfunction is a hallmark characteristic of many chronic pain syndromes, with stress-induced abnormalities to HPA axis function being highly predictive of pain chronicity [104-106]. In addition, post-surgical pain is highly dependent upon circulating levels of stress hormones. For example, although in adults, post-operative pain following arthroplastic surgery could be predicted based on stress physiology (cor- tisol and catecholamine levels, along with cardiovascular tone) prior to the surgery [107]. In addition, painful procedures in preterm neonates have been linked to reprogramming of the stress response and HPA axis, increased neuroinflammation, and cortical thinning (for review see Vinall and Grunau [108]). It is therefore plausible that ACE-induced alterations to the HPA axis would modify an adolescent's response to surgical pain in a similar fashion, thereby increasing susceptibility to the development of chronic pain.

\section{Discussion}

To summarize, ACEs increase stress and alter HPA axis function, with cortisol affecting chronic pain outcomes $[17,73,74]$. These traumatic events early in life can program changes in gene expression, cortisol receptors, and microglia response later in life $[83,89,91-93,101-$ 103]. HFHS diets also influence microglia response through persistent low-grade inflammatory activation of the neuroimmune response $[43,44]$. Like ACEs, diet can also program long-term outcomes, with dysregulation of neuroimmune function leading to overreaction to later 
stressors [48]. Chronic pain often arises in response to an acutely painful experience, such as surgery or TBI, with proposed mechanisms involving microglia priming, ionic imbalances, altered blood flow, and inflammation, all of which result in sensitization $[62,64-66]$. These areas provide promising targets for assessment and intervention, indicating that biomarkers and biological treatment strategies should focus on the inflammatory and stress responses, which may result in better management of chronic pain. See Figure 2 for summary of proposed mechanisms driving the relationship between poor diet, ACEs, and the development of chronic pain following adolescent surgery or TBI.

In conclusion, clinical research has established correlations between early life factors and adolescent pain, and preclinical research is beginning to elucidate mechanistic relationships and establish temporality. The gap in knowledge lies in elucidating neurobiological mechanisms underlying these relationships. Future studies are needed to disentangle the processes and complex interactions associated with the multiple factors that contribute to the devel- opment of adolescent chronic pain. This will lead to more effective assessment and treatment strategies, targeting particularly vulnerable individuals, which could prevent the development of chronic pain before it even begins.

\section{Disclosure Statement}

The authors have nothing to disclose.

\section{Funding Sources}

The authors would like to thank the Alberta Children's Hospital Research Institute, Canadian Institute of Health Research (PTJ - 153051), and Natural Sciences and Engineering Research Council (1304881) for their financial contributions.

\section{Author Contributions}

All authors contributed to the design, writing, and editing of the manuscript.

\section{References}

1 Finley GA, MacLaren Chorney J, Campbell L. Not small adults: the emerging role of pediatric pain services. Can J Anaesth. 2014 Feb; 61(2):180-7.

2 King S, Chambers CT, Huguet A, MacNevin RC, McGrath PJ, Parker L, et al. The epidemiology of chronic pain in children and adolescents revisited: a systematic review. Pain. 2011 Dec;152(12):2729-38.

3 Palermo TM. Impact of recurrent and chronic pain on child and family daily functioning: a critical review of the literature. J Dev Behav Pediatr. 2000 Feb;21(1):58-69.

4 Walker LS, Sherman AL, Bruehl S, Garber J, Smith CA. Functional abdominal pain patient subtypes in childhood predict functional gastrointestinal disorders with chronic pain and psychiatric comorbidities in adolescence and adulthood. Pain. 2012 Sep;153(9):1798-806.

5 Katz J, Seltzer Z. Transition from acute to chronic postsurgical pain: risk factors and protective factors. Expert Rev Neurother. 2009 May;9(5):723-44.

6 Welberg LA, Seckl JR. Prenatal stress, glucocorticoids and the programming of the brain. J Neuroendocrinol. 2001 Feb;13(2):113-28.

7 Spear LP. Adolescent neurodevelopment. J Adolesc Health. 2013 Feb;52(2 Suppl 2):S7-13.

8 Blakemore SJ, Burnett S, Dahl RE. The role of puberty in the developing adolescent brain. Hum Brain Mapp. 2010 Jun;31(6):926-33.

9 Giedd JN. The teen brain: insights from neuroimaging. J Adolesc Health. 2008 Apr;42(4): $335-43$.
10 Giedd JN, Blumenthal J, Jeffries NO, Castellanos FX, Liu H, Zijdenbos A, et al. Brain development during childhood and adolescence: a longitudinal MRI study. Nat Neurosci. 1999 Oct;2(10):861-3.

11 Steinberg L, Albert D, Cauffman E, Banich M, Graham S, Woolard J. Age differences in sensation seeking and impulsivity as indexed by behavior and self-report: evidence for a dual systems model. Dev Psychol. 2008 Nov;44(6): 1764-78.

12 Johnson SB, Blum RW, Giedd JN. Adolescent maturity and the brain: the promise and pitfalls of neuroscience research in adolescent health policy. J Adolesc Health. 2009 Sep; 45(3):216-21.

13 Casey BJ, Getz S, Galvan A. The adolescent brain. Dev Rev. 2008;28(1):62-77.

14 Paus T, Keshavan M, Giedd JN. Why do many psychiatric disorders emerge during adolescence? Nat Rev Neurosci. 2008 Dec;9(12): 947-57.

15 Kessler RC, Berglund P, Demler O, Jin R, Merikangas KR, Walters EE. Lifetime prevalence and age-of-onset distributions of DSMIV disorders in the National Comorbidity Survey Replication. Arch Gen Psychiatry. 2005 Jun;62(6):593-602.

16 Mychasiuk R, Metz GA. Epigenetic and gene expression changes in the adolescent brain: what have we learned from animal models? Neurosci Biobehav Rev. 2016 Nov;70:189-97.

17 Melzack R. Pain and the neuromatrix in the brain. J Dent Educ. 2001 Dec;65(12):1378-82.
18 Eisenberg MA, Meehan WP 3rd, Mannix R Duration and course of post-concussive symptoms. Pediatrics. 2014 Jun;133(6):999-1006.

19 Kuczynski A, Crawford S, Bodell L, Dewey D, Barlow KM. Characteristics of post-traumatic headaches in children following mild traumatic brain injury and their response to treatment: a prospective cohort. Dev Med Child Neurol. 2013 Jul;55(7):636-41.

20 Faux S, Sheedy J. A prospective controlled study in the prevalence of posttraumatic headache following mild traumatic brain injury. Pain Med. 2008 Nov;9(8):1001-11.

21 Pagé MG, Stinson J, Campbell F, Isaac L, Katz J. Identification of pain-related psychological risk factors for the development and maintenance of pediatric chronic postsurgical pain. J Pain Res. 2013;6(167): 167-80.

22 Rabbitts JA, Fisher E, Rosenbloom BN, Palermo TM. Prevalence and predictors of chronic postsurgical pain in children: a systematic review and meta-analysis. J Pain. 2017 Jun;18(6):605-14.

23 Rabbitts JA, Zhou C, Groenewald CB, Durkin L, Palermo TM. Trajectories of postsurgical pain in children: risk factors and impact of late pain recovery on long-term health outcomes after major surgery. Pain. 2015 Nov; 156(11):2383-9.

24 Sieberg CB, Simons LE, Edelstein MR, DeAngelis MR, Pielech M, Sethna N, et al. Pain prevalence and trajectories following pediatric spinal fusion surgery. J Pain. 2013 Dec; 14(12):1694-702. 
25 Kumar KH, Elavarasi P. Definition of pain and classification of pain disorders. J Adv Clin Re Insights. 2016;3(3):87-90.

26 Steeds CE. The anatomy and physiology of pain. Surgery. 2009;27(12):507-11.

27 Brooks J, Tracey I. From nociception to pain perception: imaging the spinal and supraspinal pathways. J Anat. 2005 Jul;207(1):19-33.

28 Voscopoulos C, Lema M. When does acute pain become chronic? Br J Anaesth. 2010 Dec; 105 Suppl 1:i69-85.

29 Woolf CJ, Doubell TP. The pathophysiology of chronic pain-increased sensitivity to low threshold A $\beta$-fibre inputs. Curr Opin Neurobiol. 1994 Aug;4(4):525-34.

30 Apkarian AV, Bushnell MC, Treede RD, Zubieta JK. Human brain mechanisms of pain perception and regulation in health and disease. Eur J Pain. 2005 Aug;9(4):463-84.

31 Tracey I, Mantyh PW. The cerebral signature for pain perception and its modulation. Neuron. 2007 Aug;55(3):377-91.

32 Broom DM. Evolution of pain. Vlaams Diergeneeskd Tijdschr. 2001;70(1):17-21.

33 Feizerfan A, Sheh G. Transition from acute to chronic pain. Contin Educ Anaesth Crit Care Pain. 2015;15(2):98-102.

34 Mollayeva T, Cassidy JD, Shapiro CM, Mollayeva S, Colantonio A. Concussion/mild traumatic brain injury-related chronic pain in males and females: A diagnostic modelling study. Medicine (Baltimore). 2017 Feb;96(7):e5917.

35 WHO. Obesity and overweight. Geneva: WHO; 2018.

36 Freeman LR, Haley-Zitlin V, Rosenberger DS, Granholm AC. Damaging effects of a high-fat diet to the brain and cognition: a review of proposed mechanisms. Nutr Neurosci. 2014 Nov;17(6):241-51.

37 Darmon N, Drewnowski A. Does social class predict diet quality? Am J Clin Nutr. 2008 May;87(5):1107-17.

38 Molteni R, Barnard RJ, Ying Z, Roberts CK, Gómez-Pinilla F. A high-fat, refined sugar diet reduces hippocampal brain-derived neurotrophic factor, neuronal plasticity, and learning. Neuroscience. 2002;112(4):803-14.

39 Reichelt AC, Gibson GD, Abbott KN, Hare DJ. A high-fat high-sugar diet in adolescent rats impairs social memory and alters chemical markers characteristic of atypical neuroplasticity and parvalbumin interneuron depletion in the medial prefrontal cortex. Food Funct. 2019 Apr;10(4):1985-98.

40 Pistell PJ, Morrison CD, Gupta S, Knight AG, Keller JN, Ingram DK, et al. Cognitive impairment following high fat diet consumption is associated with brain inflammation. J Neuroimmunol. 2010 Feb;219(1-2):25-32.

41 Boitard C, Maroun M, Tantot F, Cavaroc A, Sauvant J, Marchand A, et al. Juvenile obesity enhances emotional memory and amygdala plasticity through glucocorticoids. J Neurosci. 2015 Mar;35(9):4092-103.

42 Dixon JB. The effect of obesity on health outcomes. Mol Cell Endocrinol. 2010 Mar 316(2):104-8.
43 Calder PC, Ahluwalia N, Brouns F, Buetler T, Clement K, Cunningham K, et al. Dietary factors and low-grade inflammation in relation to overweight and obesity. Br J Nutr. 2011 Dec;106(S3 Suppl 3):S5-78.

44 Buckman LB, Hasty AH, Flaherty DK, Buckman CT, Thompson MM, Matlock BK, et al. Obesity induced by a high-fat diet is associated with increased immune cell entry into the central nervous system. Brain Behav Immun. 2014 Jan;35:33-42.

45 Hickman S, Izzy S, Sen P, Morsett L, El Khoury J. Microglia in neurodegeneration. Nat Neurosci. 2018 Oct;21(10):1359-69.

46 Smith JA, Das A, Ray SK, Banik NL. Role of pro-inflammatory cytokines released from microglia in neurodegenerative diseases. Brain Res Bull. 2012 Jan;87(1):10-20.

47 Peng J, Gu N, Zhou L, B Eyo U, Murugan M, Gan WB, et al. Microglia and monocytes synergistically promote the transition from acute to chronic pain after nerve injury. Nat Commun. 2016 Jun;7(1):12029.

48 Edlow AG, Glass RM, Smith CJ, Tran PK, James K, Bilbo S. Placental Macrophages: A Window Into Fetal Microglial Function in Maternal Obesity. Int J Dev Neurosci. doi: 10.1016/j.ijdevneu.2018.11.004.

49 Igosheva N, Abramov AY, Poston L, Eckert JJ, Fleming TP, Duchen MR, et al. Maternal dietinduced obesity alters mitochondrial activity and redox status in mouse oocytes and zygotes. PLoS One. 2010 Apr;5(4):e10074.

50 Yowtak J, Lee KY, Kim HY, Wang J, Kim HK, Chung K, et al. Reactive oxygen species contribute to neuropathic pain by reducing spinal GABA release. Pain. 2011 Apr;152(4): $844-52$.

51 Gao X, Kim HK, Chung JM, Chung K. Reactive oxygen species (ROS) are involved in enhancement of NMDA-receptor phosphorylation in animal models of pain. Pain. 2007 Oct; 131(3):262-71.

52 Chung JM. The role of reactive oxygen species (ROS) in persistent pain. Mol Interv. 2004 Oct;4(5):248-50.

53 Kim HK, Park SK, Zhou JL, Taglialatela G, Chung K, Coggeshall RE, et al. Reactive oxygen species (ROS) play an important role in a rat model of neuropathic pain. Pain. 2004 Sep; 111(1-2):116-24.

54 White CL, Pistell PJ, Purpera MN, Gupta S, Fernandez-Kim SO, Hise TL, et al. Effects of high fat diet on Morris maze performance, oxidative stress, and inflammation in rats: contributions of maternal diet. Neurobiol Dis. 2009 Jul;35(1):3-13.

55 Ohsawa K, Imai Y, Sasaki Y, Kohsaka S. Microglia/macrophage-specific protein Ibal binds to fimbrin and enhances its actin-bundling activity. J Neurochem. 2004 Feb;88(4): 844-56.

56 Shapiro LA, Perez ZD, Foresti ML, Arisi GM, Ribak CE. Morphological and ultrastructural features of Iba1-immunolabeled microglial cells in the hippocampal dentate gyrus. Brain Res. 2009 Apr;1266:29-36.
57 Stovitz SD, Pardee PE, Vazquez G, Duval S, Schwimmer JB. Musculoskeletal pain in obese children and adolescents. Acta Paediatr. 2008 Apr;97(4):489-93.

58 Malaty HM, Abudayyeh S, Fraley K, Graham DY, Gilger MA, Hollier DR. Recurrent abdominal pain in school children: effect of obesity and diet. Acta Paediatr. 2007 Apr;96(4): $572-6$.

59 André C, Guzman-Quevedo O, Rey C, Rémus-Borel J, Clark S, Castellanos-Jankiewicz A, et al. Inhibiting microglia expansion prevents diet-induced hypothalamic and peripheral inflammation. Diabetes. 2017 Apr;66(4): 908-19.

60 Ruskin DN, Kawamura M Jr, Masino SA. Reduced pain and inflammation in juvenile and adult rats fed a ketogenic diet. PLoS One. 2009 Dec;4(12):e8349.

61 Zhang JM, An J. Cytokines, inflammation, and pain. Int Anesthesiol Clin. 2007;45(2): 27-37.

62 Hains LE, Loram LC, Weiseler JL, Frank MG, Bloss EB, Sholar P, et al. Pain intensity and duration can be enhanced by prior challenge: initial evidence suggestive of a role of microglial priming. J Pain. 2010 Oct;11(10):1004-14. 63 Baufeld C, Osterloh A, Prokop S, Miller KR, Heppner FL. High-fat diet-induced brain region-specific phenotypic spectrum of CNS resident microglia. Acta Neuropathol. 2016 Sep;132(3):361-75.

64 Kontos AP, Reches A, Elbin RJ, Dickman D, Laufer I, Geva AB, et al. Preliminary evidence of reduced brain network activation in patients with post-traumatic migraine following concussion. Brain Imaging Behav. 2016 Jun; 10(2):594-603.

65 Heyer GL, Young JA, Rose SC, McNally KA, Fischer AN. Post-traumatic headaches correlate with migraine symptoms in youth with concussion. Cephalalgia. 2016 Apr;36(4) 309-16.

66 Bree D, Levy D. Development of CGRP-dependent pain and headache related behaviours in a rat model of concussion: implications for mechanisms of post-traumatic headache. Cephalalgia. 2018 Feb;38(2):246-58.

67 Dennis CH, Clohessy DS, Stone AL, Darnall BD, Wilson AC. Adverse Childhood Experiences in Mothers With Chronic Pain and Intergenerational Impact on Children. J Pain. 2019 Oct;20(10):1209-17.

68 Green PG, Chen X, Alvarez P, Ferrari LF, Levine JD. Early-life stress produces muscle hyperalgesia and nociceptor sensitization in the adult rat. Pain. 2011 Nov;152(11):2549-56.

69 Noel M, Wilson AC, Holley AL, Durkin L, Patton M, Palermo TM. Posttraumatic stress disorder symptoms in youth with vs without chronic pain. Pain. 2016 Oct;157(10):227784.

70 Beal SJ, Kashikar-Zuck S, King C, Black W, Barnes J, Noll JG. Heightened Risk for Pain in Young Adult Women with a History of Childhood Maltreatment: A Prospective Longitudinal Study. Pain. 2020 Jan;161(1):156-165 
71 Burke NN, Finn DP, McGuire BE, Roche M. Psychological stress in early life as a predisposing factor for the development of chronic pain: clinical and preclinical evidence and neurobiological mechanisms. J Neurosci Res. 2017 Jun;95(6):1257-70.

72 Levine S. Developmental determinants of sensitivity and resistance to stress. Psychoneuroendocrinology. 2005 Nov;30(10):939-46.

73 Aisa B, Tordera R, Lasheras B, Del Río J, Ramírez MJ. Cognitive impairment associated to HPA axis hyperactivity after maternal separation in rats. Psychoneuroendocrinology. 2007 Apr;32(3):256-66.

74 Kalinichev M, Easterling KW, Plotsky PM, Holtzman SG. Long-lasting changes in stressinduced corticosterone response and anxietylike behaviors as a consequence of neonatal maternal separation in Long-Evans rats. Pharmacol Biochem Behav. 2002 Aug;73(1): $131-40$.

75 Ulrich-Lai YM, Xie W, Meij JT, Dolgas CM, Yu L, Herman JP. Limbic and HPA axis function in an animal model of chronic neuropathic pain. Physiol Behav. 2006 Jun;88(1-2): 67-76.

76 Wippert PM, Rector M, Kuhn G, Wuertz-Kozak K. Stress and alterations in bones: an interdisciplinary perspective. Front Endocrinol (Lausanne). 2017 May;8(96):96.

77 Madigan S, Wade M, Plamondon A, Maguire JL, Jenkins JM. Maternal adverse childhood experience and infant health: biomedical and psychosocial risks as intermediary mechanisms. J Pediatr. 2017 Aug; 187:282-289.e1.

78 Flory JD, Bierer LM, Yehuda R. Maternal exposure to the holocaust and health complaints in offspring. Dis Markers. 2011;30(2-3):1339.

79 Yehuda R, Halligan SL, Bierer LM. Relationship of parental trauma exposure and PTSD to PTSD, depressive and anxiety disorders in offspring. J Psychiatr Res. 2001 Sep-Oct; 35(5):261-70

80 Appleyard K, Berlin LJ, Rosanbalm KD, Dodge KA. Preventing early child maltreatment: implications from a longitudinal study of maternal abuse history, substance use problems, and offspring victimization. Prev Sci. 2011 Jun;12(2):139-49.

81 Helgeland H, Sandvik L, Mathiesen KS, Kristensen $\mathrm{H}$. Childhood predictors of recurrent abdominal pain in adolescence: A 13-year population-based prospective study. J Psychosom Res. 2010 Apr;68(4):359-67.

82 Davis EP, Glynn LM, Waffarn F, Sandman CA. Prenatal maternal stress programs infant stress regulation. J Child Psychol Psychiatry. 2011 Feb;52(2):119-29.

83 Diz-Chaves Y, Astiz M, Bellini MJ, GarciaSegura LM. Prenatal stress increases the expression of proinflammatory cytokines and exacerbates the inflammatory response to LPS in the hippocampal formation of adult male mice. Brain Behav Immun. 2013 Feb;28: 196-206.
84 Goldberg RT, Pachas WN, Keith D. Relationship between traumatic events in childhood and chronic pain. Disabil Rehabil. 1999 Jan; 21(1):23-30.

85 Goldberg RT, Goldstein R. A comparison of chronic pain patients and controls on traumatic events in childhood. Disabil Rehabil. 2000 Nov;22(17):756-63.

86 Sachs-Ericsson N, Kendall-Tackett K, Hernandez A. Childhood abuse, chronic pain, and depression in the National Comorbidity Survey. Child Abuse Negl. 2007 May;31(5): 531-47.

87 Jones GT, Power C, Macfarlane GJ. Adverse events in childhood and chronic widespread pain in adult life: Results from the 1958 British Birth Cohort Study. Pain. 2009 May; 143(1-2):92-6.

88 Lampe A, Doering S, Rumpold G, Sölder E, Krismer M, Kantner-Rumplmair W, et al. Chronic pain syndromes and their relation to childhood abuse and stressful life events. J Psychosom Res. 2003 Apr;54(4):361-7.

89 Baumeister D, Akhtar R, Ciufolini S, Pariante CM, Mondelli V. Childhood trauma and adulthood inflammation: a meta-analysis of peripheral C-reactive protein, interleukin-6 and tumour necrosis factor- $\alpha$. Mol Psychiatry. 2016 May;21(5):642-9.

90 McGowan PO, Sasaki A, D’Alessio AC, Dymov S, Labonté B, Szyf M, et al. Epigenetic regulation of the glucocorticoid receptor in human brain associates with childhood abuse. Nat Neurosci. 2009 Mar;12(3):342-8.

91 Banqueri M, Méndez M, Arias JL. Behavioral effects in adolescence and early adulthood in two length models of maternal separation in male rats. Behav Brain Res. 2017 May;324: 77-86.

92 Vilela FC, Vieira JS, Giusti-Paiva A, Silva ML Experiencing early life maternal separation increases pain sensitivity in adult offspring. Int J Dev Neurosci. 2017 Nov;62(1):8-14.

93 Burke NN, Llorente R, Marco EM, Tong K, Finn DP, Viveros MP, et al. Maternal deprivation is associated with sex-dependent alterations in nociceptive behavior and neuroinflammatory mediators in the rat following peripheral nerve injury. J Pain. 2013 Oct;14(10): 1173-84.

94 Mizoguchi H, Fukumoto K, Sakamoto G, Jin S, Toyama A, Wang T, et al. Maternal separation as a risk factor for aggravation of neuropathic pain in later life in mice. Behav Brain Res. 2019 Feb;359:942-9.

95 Gracia-Rubio I, Moscoso-Castro M, Pozo OJ, Marcos J, Nadal R, Valverde O. Maternal separation induces neuroinflammation and long-lasting emotional alterations in mice. Prog Neuropsychopharmacol Biol Psychiatry. 2016 Feb;65:104-17.

96 Stone AL, Wilson AC. Transmission of risk from parents with chronic pain to offspring: an integrative conceptual model. Pain. 2016 Dec;157(12):2628-39.
97 Niederland T, Makovi H, Gál V, Andréka B, Abrahám CS, Kovács J. Abnormalities of pituitary function after traumatic brain injury in children. J Neurotrauma. 2007 Jan;24(1): 119-27.

98 Yamakawa GR, Weerawardhena H, Eyolfson E, Griep Y, Antle MC, Mychasiuk R. Investigating the Role of the Hypothalamus in Outcomes to Repetitive Mild Traumatic Brain Injury: Neonatal Monosodium Glutamate Does Not Exacerbate Deficits. Neuroscience. 2019 Aug;413:264-78.

99 Nelson CA 3rd, Gabard-Durnam LJ. Early Adversity and Critical Periods: Neurodevelopmental Consequences of Violating the Expectable Environment. Trends Neurosci. 2020 Mar;43(3):133-43.

100 Peres MF, Sanchez del Rio M, Seabra ML, Tufik S, Abucham J, Cipolla-Neto J, et al. Hypothalamic involvement in chronic migraine. J Neurol Neurosurg Psychiatry. 2001 Dec;71(6):747-51.

101 Alexander JK, DeVries AC, Kigerl KA, Dahlman JM, Popovich PG. Stress exacerbates neuropathic pain via glucocorticoid and NMDA receptor activation. Brain Behav Immun. 2009 Aug;23(6):851-60.

102 Bradesi S, Svensson CI, Steinauer J, Pothoulakis C, Yaksh TL, Mayer EA. Role of spinal microglia in visceral hyperalgesia and NK1R up-regulation in a rat model of chronic stress. Gastroenterology. 2009 Apr;136(4): 1339-48.

103 Beggs S, Currie G, Salter MW, Fitzgerald M, Walker SM. Priming of adult pain responses by neonatal pain experience: maintenance by central neuroimmune activity. Brain. 2012 Feb;135(Pt 2):404-17.

104 Kuehl LK, Michaux GP, Richter S, Schächinger $\mathrm{H}$, Anton F. Increased basal mechanical pain sensitivity but decreased perceptual wind-up in a human model of relative hypocortisolism. Pain. 2010 Jun;149(3):539-46.

105 McBeth J, Silman AJ, Gupta A, Chiu YH, Ray D, Morriss R, et al. Moderation of psychosocial risk factors through dysfunction of the hypothalamic-pituitary-adrenal stress axis in the onset of chronic widespread musculoskeletal pain: findings of a populationbased prospective cohort study. Arthritis Rheum. 2007 Jan;56(1):360-71.

106 Crofford LJ, Pillemer SR, Kalogeras KT, Cash JM, Michelson D, Kling MA, et al. Hypothalamic-pituitary-adrenal axis perturbations in patients with fibromyalgia. Arthritis Rheum. 1994 Nov;37(11):1583-92.

107 Cremeans-Smith JK, Greene K, Delahanty DL. Physiological indices of stress prior to and following total knee arthroplasty predict the occurrence of severe post-operative pain. Pain Med. 2016 May;17(5):970-9.

108 Vinall J, Grunau RE. Impact of repeated procedural pain-related stress in infants born very preterm. Pediatr Res. 2014 May;75(5): 584-7. 